\title{
Impact of Blanket Configuration on the Design of a Fusion- Driven Transmutation Reactor
}

\author{
Bong Guen Hong*
}

Chonbuk National University, 567 Baekje-daero, deokjin-gu, Jeonju-si, Jeollabuk-do, 54896 Korea

\begin{abstract}
A configuration of a fusion-driven transmutation reactor with a low aspect ratio tokamak-type neutron source was determined in a self-consistent manner by using coupled analysis of tokamak systems and neutron transport. We investigated the impact of blanket configuration on the characteristics of a fusion-driven transmutation reactor. It was shown that by merging the TRU burning blanket and tritium breeding blanket, which uses PbLi as the tritium breeding material and as coolant, effective transmutation is possible. The TRU transmutation capability can be improved with a reduced blanket thickness, and fast fluence at the first wall can be reduced.
\end{abstract}

Keywords: Tokamak neutron source, Transmutation reactor, Low aspect ratio tokamak, Systems analysis

Article History: Received: July 10 th 2017; Received: Dec 17 ${ }^{\text {th }}$ 2017; Accepted: February $2^{\text {nd }}$ 2018; Available online

How to Cite This Article: Hong, B.G. (2018) Impact of Blanket Configuration on the Design of a Fusion-Driven Transmutation Reactor. International Journal of Renewable Energy Development, 7(1), 65-70.

https://doi.org/10.14710/ijred.7.1.65-70

\section{Introduction}

A tokamak has been used as a high energy (14 MeV) neutron source for conceptual studies (Wu et al. 2006, Stacey 2007, Hong 2014) of a transmutation reactor that can burn radioactive waste (radwaste) contained in spent fuel. Depending on the radwaste management strategy, fission products are separated from spent fuel, and only transuranic (TRU) actinides ( $\mathrm{Pu}$ and minor actinides) can be burned (Song et al. 2010). The transmutation reactor must burn as much radwaste as possible by converting some of the TRUs into nuclides that are stable, have shorter half-lives, or are less hazardous. The low aspect ratio (LAR) tokamak (Hong et al. 2011, Najmabadi et al. 2003, Nishitani et al. 2006) is a viable option for the fusion neutron source because it allows both a large elongated plasma shape that is favorable for the transmutation reactor and a high plasma beta, which enables a high-performance compact reactor. In the LAR tokamak, it was shown (Hong et al. 2011) that the tritium self-sufficiency can be satisfied with the outboard tritium breeding blanket only.

Both plasma physics and engineering constraints for each component of the reactor must be considered to determine optimal dimensions of the transmutation reactor. Furthermore, these constraints must be simultaneously satisfied by the reactor components.
For a given fusion power a large toroidal magnetic field at the plasma center $\left(\mathrm{B}_{\mathrm{T}}\right)$ allows a smaller major radius and thus a smaller reactor size. To increase $B_{T}$, the distance between the toroidal field (TF) coil and the plasma must be reduced, while enough shielding for the superconducting TF coil shield is also required. Thus to determine the reactor parameters and the dimensions of the reactor components of the fusiondriven transmutation reactor in a self-consistent manner, a systems analysis coupled with neutron transport calculations (Hong et al. 2008, Hong and Oh 2015) has to be performed.

In the transmutation reactor with the LAR tokamak-type based neutron source, the TRU can only be loaded in the outboard blanket. Inboard radial dimensions of the reactor components are obtained from plasma physics, tokamak engineering, and neutron shielding constraints, while the outboard radial dimensions of the reactor components are determined by considering the constraints related to neutron multiplication, the tritium-breeding ratio, neutron damage, power density, and neutron flux. In this study, we compared the characteristics of a fusion-driven transmutation reactor for arrangements in which the TRU burning blanket and tritium breeding blanket are separate or merged.

\footnotetext{
* Corresponding author: bghong@jbnu.ac.kr
} 
Model of the transmutation reactor is explained in Sec. 2. The analysis method and optimal size of the transmutation reactor with the LAR tokamak-type neutron source is shown in Sec. 3. We show the impact of the blanket configurion and in Sec. 4.

\section{Model of the Fusion-Driven Transmutation Reactor}

One-dimensional cylindrical model of the transmutation reactor is shown in Fig. 1 with the material and composition of the reactor components shown in Table 1. Water was selected as the coolant for most of reactor components except for the blankets in which $\mathrm{He}$ or $\mathrm{PbLi}$ were used. We assumed that the plasma current is ramped up and maintained by a current drive system, and thus there is no central solenoid coil. We also considered a transmutation reactor with a LAR tokamak-type based neutron source and only the outboard blanket.

Table 1

Material and composition of transmutation reactor components.

\begin{tabular}{|c|c|}
\hline Component & Materials (Volume\%) \\
\hline Toroidal field coil & SUS316, L. He, Nbssn, Cu, Epoxy \\
\hline Vacuum vessel & Borated steel (60), $\mathrm{H}_{2} \mathrm{O}(40)$ \\
\hline Shield & $\mathrm{WC}(80), \mathrm{H}_{2} \mathrm{O}(20)$ \\
\hline First wall & FMS (60), $\mathrm{H}_{2} \mathrm{O}(40)$ \\
\hline Scrape-off layer & - \\
\hline Plasma & $\mathrm{D}, \mathrm{T}$ \\
\hline Scrape-off layer & - \\
\hline First wall & FMS (60), $\mathrm{H}_{2} \mathrm{O}(40)$ \\
\hline \multicolumn{2}{|l|}{ [Case1] } \\
\hline TRU burning blanket & TRU (5), He (75), FMS (15), SiC (5) \\
\hline Breeding blanket & He (7), PbLi (90), FMS (3) \\
\hline \multicolumn{2}{|l|}{ [Case 2] } \\
\hline TRU burning blanket & TRU (5), PbLi (75), FMS (15), SiC (5) \\
\hline High temp. shield & $\mathrm{WC}(60), \mathrm{H}_{2} \mathrm{O}(40)$ \\
\hline Low temp. shield & WC (80), $\mathrm{H}_{2} \mathrm{O}(20)$ \\
\hline Vacuum vessel & Borated steel (60), $\mathrm{H}_{2} \mathrm{O}(40)$ \\
\hline Toroidal field coil & $\mathrm{Nb}_{3} \mathrm{Sn}, \mathrm{Cu}$, Epoxy, SUS316, L. He \\
\hline
\end{tabular}

The superconducting magnet and vacuum vessel designs employed International Thermonuclear Experimental Reactor (ITER) technology (Mitchell et al. 2012, Holtkamp 2009). The TF coil was made of an $\mathrm{Nb}_{3} \mathrm{Sn}$ superconductor. The toroidal magnetic field, the current density at that field, and neutron damage to the superconductor determine the radial dimension of the TF coil. The vacuum vessel was made of a borated stainless steel. The first wall was made of ferritic-martensitic stainless steel (FMS). Depending on the accumulated fast neutron fluence from both fusion and fission, the first wall has to be replaced during the lifetime of the reactor. The fast neutron fluence limit of the FMS was set to be $3.0 \times 10^{27} \mathrm{n} \cdot \mathrm{m}^{-2}$.

The shield should sufficiently protect the superconducting toroidal field (TF) coil from damage induced by both fusion and fission neutrons. The shield was made from WC, and its thickness was determined by the shielding requirement for the protection of the TF coil from the neutron damage. The constraints used in this study were fast neutron fluence to the superconductor less than $10^{23} \mathrm{n} \cdot \mathrm{m}^{-2}$ for
$\mathrm{Nb}_{3} \mathrm{Sn}$, a dose to the insulators less than $10^{9} \mathrm{rad}$ for organic insulators, and a displacement damage to the $\mathrm{Cu}$ stabilizer less than $5 \times 10^{-4} \mathrm{dpa}$. The design lifetime and availability of the transmutation reactor were set to be 40 years and $75 \%$, respectively.

Space for the blankets should be sufficient to maximize the transmutation and tritium breeding capability, and to keep the power density less than $100 \mathrm{MW} \cdot \mathrm{m}^{-3}$. The TRU from spent fuel of the $1 \mathrm{GWe}$ Korea Standard Nuclear Power plant (KSNP) whose nuclide composition is given in Ref. (Hong 2014) was loaded for transmutation in the TRU burning blanket. SUS316LN coated with $\mathrm{SiC}$ was used as a structural material of the blanket, and $\mathrm{He}$ was used as its coolant. PbLi was used as the tritium breeding material and coolant. Natural Li can be used, since there are enough thermal neutrons produced from fission of TRU to ensure tritium self-sufficiency. We considered two blanket models. In Case 1, the TRU burning blanket and tritium breeding blanket were separate, as shown in Fig. 1(a), and in Case 2, the 
TRU burning blanket and the tritium breeding blanket were merged, as shown in Fig. 1(b).

(a)

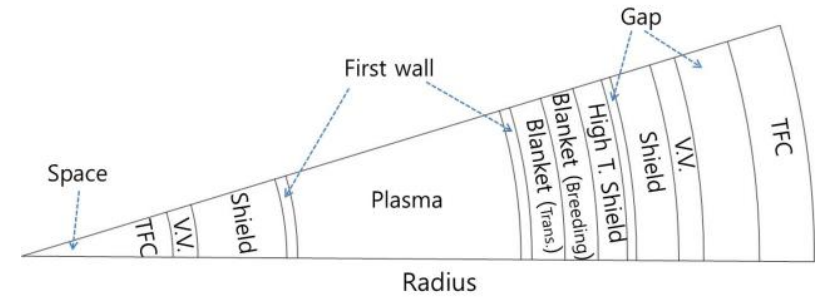

(b)

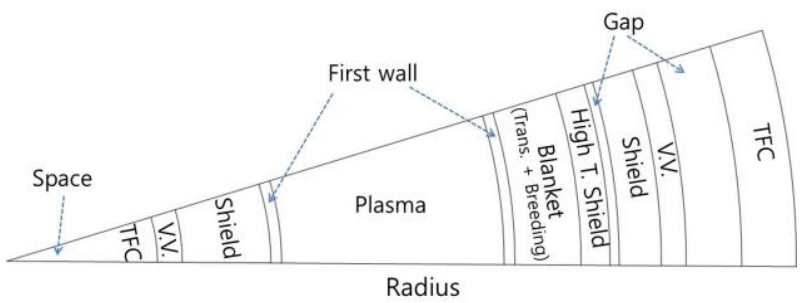

Fig. 1 One-dimensional cylindrical model of the transmutation reactor: (a) Case 1 and (b) Case 2.

\section{Optimal Size of a Transmutation Reactor with a LAR Tokamak-type Neutron Source}

The LAR tokamak allows elongated, high beta plasma, which improves the magnetohydrodynamic (MHD) stability and confinement characteristics. In this study, we used expressions of plasma performance such as the plasma density limit, beta limit, and plasma current limit, which is imposed by a limitation on the edge safety factor $q$, the maximum elongation, and the maximum $\beta_{\mathrm{N}}$, which were derived in Refs. (Menard et al. 2003, Wong et al. 2002, Lin-Liu and Stambaugh 2002).

A tokamak systems analysis coupled with a neutron transport calculation (Hong 2014, Hong and Oh 2015) was utilized for self-consistent determination of the dimensions of the reactor components. In Table 2 , we show the set of variables and constraints which were selected in the coupled systems analysis. The first four constraints, beta limit, density limit, power balance, and required fusion power, determine electron density, electron temperature, auxiliary heating power, and the major radius. The inboard radial dimension of the reactor components was determined from plasma physics, tokamak engineering constraints, and neutron shielding requirements. With the desired fusion power given, the constraints on the TF coil such as the neutron shielding, the TF coil critical current density, the TF coil case stress, the Ampere's law, and the radial build constraint determine the shield thickness, the TF coil thickness, the TF coil current density, and the TF coil case thickness.

The radial dimensions and the reactor parameters for the maximum fusion power $=100 \mathrm{MW}$ and two cases of the aspect ratio (A) were found with the blanket model of Case 1 as shown in Table 3.

Table 2

Set of variables and constraints selected in the systems analysis. Constraint Variable

[Plasma physics]

(1) Beta limit, $\beta_{\mathrm{N}}<\beta_{\mathrm{N}, \mathrm{ma}} \xi$

(2) Density limit, $\mathrm{n}_{\mathrm{e}}<\mathrm{n}$ Greenwald

(3) Power balance equation, $\mathrm{P}_{\text {con }}+\mathrm{P}_{\text {rad }}=\mathrm{P}_{\alpha}+\mathrm{P}_{\text {aux }}$

(1) Electron density, $\mathrm{n}_{\mathrm{e}}$

(2) Electron temperature, $\mathrm{T}_{\mathrm{e}}$

(4) Fusion power, $\mathrm{P}_{\text {fusion }}=$ fusion power

(3) Auxiliary heating power, $\mathrm{P}_{\text {aux }}$

(4) Major radius, $R_{0}$

[Engineering]

(5) Shielding requirements for $\mathrm{TF}$ coil

(5) Shield thickness, $\Delta_{\text {SHLD }}$

fast neutron fluence in superconductor $<10^{23} \mathrm{n} \cdot \mathrm{m}^{-2}$

displacement damage in $\mathrm{Cu}$ stabilizer $<5 \times 10^{-4} \mathrm{dpa}$ dose to the insulators $<10^{9} \mathrm{rad}$

(6) Ampere's law, $B_{\max } \times R_{T F C}=B_{T} \times R_{o}$

(6) $\mathrm{TF}$ coil thickness, $\Delta_{\mathrm{TFC}}$

(7) $\mathrm{TF}$ coil current density (7) TF coil current density, constraint, $\mathrm{J}_{\mathrm{TFC}}$ $\mathrm{J}_{\mathrm{TF}}<2.8 \times 10^{8} \mathrm{~A} \cdot \mathrm{m}^{-2}$

(8) $\mathrm{TF}$ coil case stress constraint, $\sigma<550 \mathrm{MPa}$

(9) Radial build

(8) $\mathrm{TF}$ coil case thickness, $\Delta_{\text {TFcase }}$

(9) Bore radius of $\mathrm{TF}$ coil, $\mathrm{R}_{\text {bore }}$

Table 3

Radial dimension and reactor parameters of the transmutation reactor.

\begin{tabular}{lcc}
\hline Reactor parameters & $\mathbf{A}=\mathbf{1 . 5}$ & $\mathbf{A}=\mathbf{2 . 0}$ \\
\hline$\Delta_{\mathrm{TFC}}(\mathrm{m})$ & 0.28 & 0.39 \\
$\Delta_{\mathrm{VV}}(\mathrm{m})$ & 0.15 & 0.15 \\
$\Delta_{\Sigma \mathrm{HLD}}(\mathrm{m})$ & 0.40 & 0.53 \\
Minor radius, a $(\mathrm{m})$ & 1.89 & 1.20 \\
Major radius, $\mathrm{R}(\mathrm{m})$ & 2.84 & 2.39 \\
Elongation, $\kappa$ & 3.2 & 2.76 \\
Magnetic field, $\mathrm{B}_{\mathrm{T}}(\mathrm{T})$ & 0.94 & 1.88 \\
qedge & 2.6 & 2.8 \\
$\beta_{\mathrm{N}}$ & 8.3 & 7.1 \\
Auxiliary heating $(\mathrm{MW})$ & 105 & 108 \\
\hline
\end{tabular}

To produce a given fusion power, an edge safety factor, qedge, a normalized plasma beta, $B_{\mathrm{N}}$, a confinement enhancement factor, $\mathrm{H}$, and a plasma density, $\mathrm{n}$ were determined to allow the maximum performance, i.e., qedge $=q_{\text {edge, } \min }, B_{N}=B_{N, \max }, H=1.2$ and 
$\mathrm{n}=\mathrm{n}_{\mathrm{G}}$, where $\mathrm{n}_{\mathrm{G}}$ is Greenwald density limit. The shield thickness was mainly determined by the neutron dose limit of the TF coil insulator and it increases when the aspect ratio or the fusion power increases because of the large neutron wall loading. With TRUs loaded in the TRU burning blanket, the inboard shield thickness increases as compared with the case without loaded TRUs since neutrons from the fission of TRUs affect the shielding. A smaller shield thickness (and thus a smaller major radius) was obtained for Case 2 due to the smaller effect from fission neutrons, which will be discussed further in Sec. 4.

\section{Effect of the Blanket Model on the Transmutation Characteristics}

The outboard radial dimension of the reactor components was determined to satisfy the constraints: maximum neutron multiplication, $\mathrm{k}_{\text {eff }}$ less than 0.95 (for sub-criticality); maximum power density less than $100 \mathrm{MW} \cdot \mathrm{m}^{-3}$; and tritium breeding ratio $(\mathrm{TBR})>1.35$ (in the one-dimensional calculation with a blanket coverage factor of $80 \%$ assumed). The one-dimensional neutron transport code, BISON-C (ORNL 1998), with a JENDL-3 (Nakagawa et al. 1995) based 42 neutron group cross-section library on was used to calculate the neutron flux and the nuclide density.

Table 4

Transmutation characteristics for the five-batch equilibrium fuel cycle.

\begin{tabular}{cccc}
\hline $\begin{array}{c}\text { Aspect } \\
\text { ratio }\end{array}$ & Case 1 & Case 2 \\
\hline & Trans. rate $(\mathrm{kg} / \mathrm{y})$ & 848 & 1,044 \\
& Total power $(\mathrm{MW})$ & 3,000 & 3,630 \\
& Fast fluence @ $\mathrm{FW}\left(10^{27} \mathrm{n} \cdot \mathrm{m}^{-2}\right)$ & 0.6 & 0.3 \\
& Lifetime of FW (y) & 27.4 & 54.8 \\
& $\Delta_{\mathrm{BL} 1}(\mathrm{~m})$ & 0.2 & 0.19 \\
& $\Delta_{\mathrm{BL} 2}(\mathrm{~m})$ & 0.2 & $\mathrm{n} / \mathrm{a}$ \\
& Trans. rate $(\mathrm{kg} / \mathrm{y})$ & 573 & 762 \\
& Total power $(\mathrm{MW})$ & 2,040 & 2,669 \\
& Fast fluence @ $\mathrm{FW}\left(10^{27} \mathrm{n} \cdot \mathrm{m}^{-2}\right)$ & 0.9 & 0.5 \\
& Lifetime of FW $(\mathrm{y})$ & 18.3 & 32.9 \\
& $\Delta_{\mathrm{BL} 1}(\mathrm{~m})$ & 0.26 & 0.33 \\
& $\Delta_{\mathrm{BL} 2}(\mathrm{~m})$ & 0.2 & $\mathrm{n} / \mathrm{a}$ \\
\hline
\end{tabular}

The transmutation reactor burns the TRU and produces power due to the fission reaction of the TRU. For a large, constant power, $\mathrm{k}_{\text {eff }}$ should be kept large and constant during the TRU burn-up period or the fusion power must be increased to compensate for consumption of neutrons, since the produced power is proportional to $\mathrm{P}_{\text {fusion }} \cdot \mathrm{k}_{\text {eff }} /\left(1-\mathrm{k}_{\text {eff }}\right)$. Figure 2 shows the variation of $k_{\text {eff }}$ as the TRU is burned when the total power, which is a sum of the fusion power and fission power, is 3,000 MW and $\mathrm{A}=1.5$ with a maximum fusion power $=100 \mathrm{MW}$. The neutron multiplication, $\mathrm{k}_{\text {eff }}$ decreases as the TRU is burned. The variation in keff was large for Case 1, and the required fusion power reaches $100 \mathrm{MW}$ at a burn-up of 900 days, while the variation in $\mathrm{k}_{\text {eff }}$ was small for Case 2 , and the required fusion power was less than $100 \mathrm{MW}$ at a burn-up of 1,000 days.

An equilibrium fuel cycle that transmutes TRUs in five burn cycles was developed to effectively transmute nuclear waste (Hong 2014). At the given maximum fusion power, a five-batch equilibrium fuel cycle limits the total power and transmutation capability. In addition, the fast wall must be replaced before the fast neutron fluence during five cycle residence times reaches the fast neutron fluence limit of the FMS.

(a)

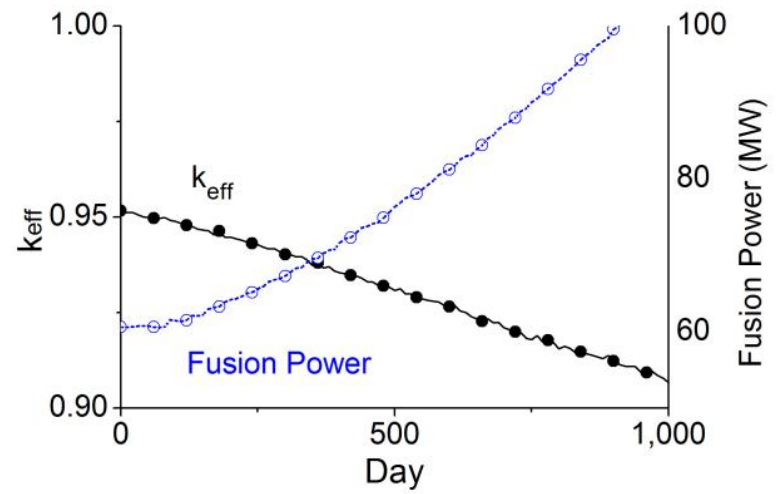

(b)

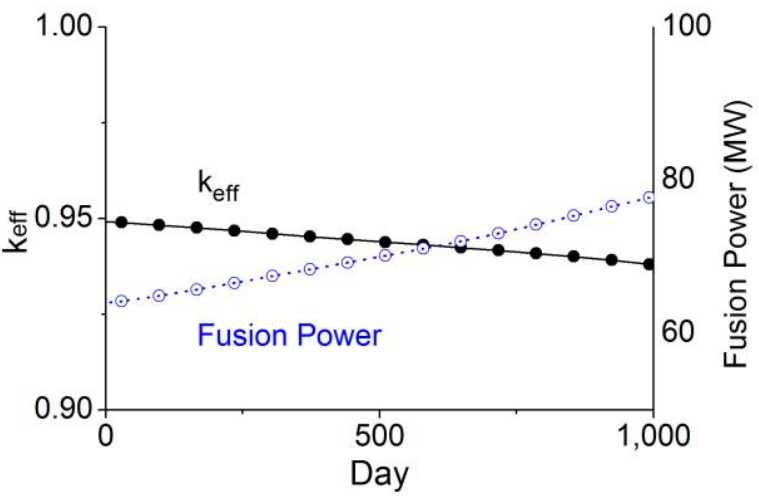

Fig. 2 Variation of $\mathrm{k}_{\text {eff }}$ with TRU burn when $\mathrm{A}=1.5$ and total power $=3,000 \mathrm{MW}$ : (a) Case 1 and (b) Case 2 .

In Table 4, we compare the transmutation characteristics for the two blanket models with the transmutation reactor operating at full capacity and with the burn cycle of 300 days. The reactor height was assumed to be $\kappa \cdot \alpha$, where $\kappa$ is the plasma elongation and $\alpha$ is the minor radius. The transmutation rate, which is defined as the total mass reduction of the TRU per year, was larger for smaller 
aspect ratios. Also, the transmutation rate for Case 2 was larger than for Case 1. The fast neutron fluence over the five cycle residence times was larger, and the lifetime of the first wall was shorter with larger aspect ratio $A$. The radial thicknesses of the TRU burning blanket for Case 2 was smaller than the total radial thickness of the TRU burning blanket plus the tritium-breeding blanket for Case 1. The TBR for Case 2 was larger than for Case 1.

(a)

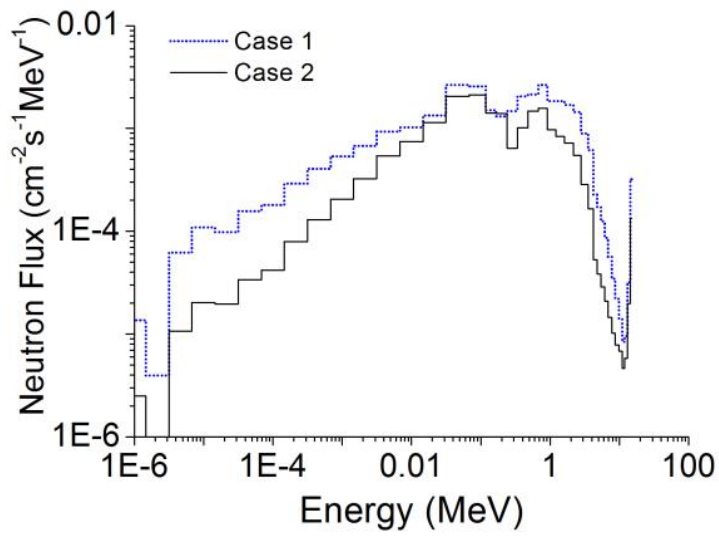

(b)

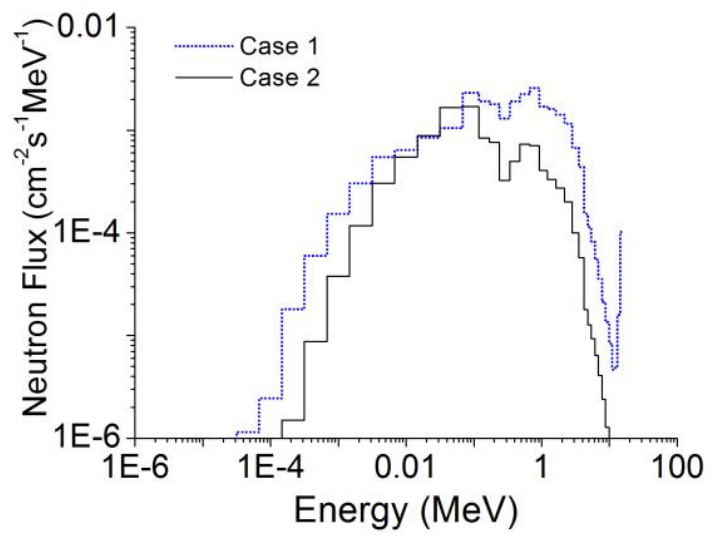

Fig. 3 Neutron spectra when $\mathrm{A}=1.5$ and the maximum fusion power $=100 \mathrm{MW}$ : (a) front and (b) back region of the blanket.

Figure 3 shows the neutron energy spectrum after the fifth burn cycle for $\mathrm{A}=1.5$ with a maximum fusion power $=100 \mathrm{MW}$ in the (a) front and (b) back regions of the TRU burning blanket for the two cases. Neutron flux in the back region became smaller as high energy neutrons transmute the TRUs or slow down. Neutron flux was lower for Case 2 than for Case 1. The low energy neutron flux in Case 2 was small since it contributes to tritium breeding due to the large tritium breeding cross section of Li-6 with low energy neutrons. High energy neutrons can cause the $(\mathrm{n}, 2 \mathrm{n})$ reaction with $\mathrm{Pb}$, and the multiplied neutrons contribute to transmutation of the TRUs, as shown in Fig. 4(b). Thus, with the TRU burning blanket and tritium breeding blanket merged, effective transmutation is possible, and the radial thickness of the blanket can be reduced.

\section{Conclusion}

The optimum radial dimension of the transmutation reactor with a LAR tokamak-type neutron source was determined through the coupled analysis of the tokamak systems and neutron transport. The radial build of the reactor components was self-consistently determined by simultaneously satisfying the constraints related to plasma physics performance, tokamak engineering, and neutronic performance.

By merging the TRU burning blanket and tritium breeding blanket, which uses $\mathrm{PbLi}$ as the tritium breeding material and coolant, the variation of $\mathrm{k}_{\text {eff }}$ was small due to a favorable neutron spectrum and the total power increases. The TRU transmutation capability can be improved with a reduced blanket thickness, and fast fluence at the first wall can be reduced.

\section{Acknowledgments}

This work was supported by the "Research Base Construction Fund Support Program" funded by Chonbuk National University in 2017. This work was also supported by a National Research Foundation of Korea (NRF) grant under contract nos. 2015R1D1A3A01019752 and 2017M1A7A1A02016138, and by research facilities at the Plasma Application Institute of Chonbuk National University.

\section{References}

Holtkamp N. (2009), The status of the ITER design, Fusion Engineering and Design, 84, 98.

Hong B.G. (2014), Conceptual study of fusion-driven system for nuclear waste transmutation, Fusion Engineering and Design, 89, 2493.

Hong B.G. Hwang, Y.S., Kang, J.S., Lee, D.W., Joo, H.G., Ono, M. (2011), Conceptual design study of a superconducting spherical tokamak reactor with a self-consistent system analysis code, Nucl. Fusion, 51, 113013.

Hong B.G., Lee D.W. and In S.R. (2008), Tokamak Reactor System Analysis Code for the Conceptual Development of DEMO Reactor, Nuclear Engineering and Technology, 40, 1.

Hong,B.G.. and Oh, P. (2015), Characteristics of nuclear waste transmutation based on a tokamak neutron source, Int. J. Hydrogen Energy, 40, 1515.

Lin-Liu Y. and Stambaugh R. (2002), Optimum plasma states for next step tokamaks, General Atomics Report, GA-A23980.

Menard J., Bell, M.G., Bell, R.E., Gates, D.A., Kaye, S.M., LeBlanc, B.P., Sabbagh, S.A., Fredrickson, E.D., Jardin, S.C.; Maingi, R.; Manickam, J.; Mueller, D.; Ono, M., Paoletti, F., Peng, Y.-K.M., Soukhanovskii, V., Stutman, D., Synakowski, E.J. (2003), Unified ideal stability limits for 
advanced tokamak and spherical torus plasmas, Princeton Plasma Physics Laboratory Report, PPPL-3779.

Mitchell N., Devred, A., Libeyre, P. (2012), The ITER Magnets: Design and Construction Status, IEEE Transactions on Applied Superconductivity, 22, 4200809.

Najmabadi F. and The ARIES Team (2003), Fusion Eng. Des. $65,143$.

Nakagawa T., Asami, T. (1995) Japanese evaluated nuclear data library version 3 reversion-2: JENDL-3.2, Journal of Nuclear Science and Technology, 32, 1259.

Nishitani T., Yamauchi M., Nishio S. and Wada M. (2006), Fusion Eng. Des. 81, 1245.

ORNL (1998), BISON-C, Oak Ridge National Laboratory.Report, CCC-659.
Song K.C., Lee, H., Hur, J-M., KIM, J.G., Ahn, D.H. and Cho, Y.Z. (2010), Status of Pyroprocessing Technology Development in Korea, Nuclear Engineering and Technology, $42,131$.

Stacey W.M. (2007), Transmutation missions for fusion neutron sources, Fusion Engineering and Design, 82, 11.

Wong C., Wesley, J.C., Stambaugh, R.D. and Cheng, E.T. (2002), Toroidal reactor designs as a function of aspect ratio and elongation, Nucl. Fusion, 42, 547.

Wu,Y. Zheng, S., Zhu, X., Wang, W., Liu, S., Bai, Y., Chen, H., Hu, L., Chen, M., Huang, Q., Huang, D., Zhang, S., Li, J., Chu, D., Jiang, J., Song, Y. (2006), Conceptual design of the fusion-driven subcritical system FDS-I, Fusion Engineering and Design, 81, 1305. 